\title{
Darwinismo e raça em Feliciano Pinheiro de Bittencourt
}

\section{Darwinism and race in Feliciano Pinheiro de Bittencourt}

\author{
KAROLINE CARULA \\ Universidade do Estado do Rio de Janeiro | UERJ
}

\begin{abstract}
RESUMO O darwinismo, entre 1870 e 1880, passou a ser propagado nas Conferências Populares da Glória, local que se caracterizou como espaço público de vulgarização científica no Rio de Janeiro. Defensores e detratores apresentavam suas concepções a respeito da nova teoria. Dentre aqueles foram contrários ao paradigma de Darwin, merece destaque o médico Feliciano Pinheirode Bittencourt - orador que mais preleçõesrealizou. Desta maneira, este artigo apresenta e analisa as conferências de Bittencourt, identificando, em suas falas, sua crítica ao darwinismo, bem como seu posicionamento poligenista e criacionista. Também é salientada sua leitura da sociedade, pautada em uma interpretação racializada.
\end{abstract}

Palavras-chave darwinismo - raça - poligenismo - criacionismo.

\begin{abstract}
During the years of 1870 and 1880, the theory of Darwinism was widely propagated in the Popular Conferences of Glória. These conferences were known as public spaces for the diffusion of scientific debates in Rio de Janeiro. Throughout the many discussions from the Conferences, several defenders and detractors of Darwinism expressed their provocative views on the theory. Among those who were opposed to the Darwinian paradigm, I highlight the thoughts of Dr. Feliciano Pinheiro de Bittencourt - the lecturer who was responsible for most of the conferences. This paper presents and analyzes the lectures of Dr. Bittencourt identifying, through his speeches, his criticism of Darwinism, as well as his standing as a believer in polygenism and creationism. In this paper, I also examine his interpretation of the society from a racialized perspective.
\end{abstract}

Keywords Darwinism - race - polygenism - creationism.

\section{Introdução}

Nas décadas de 1870 e 1880, ocorreram as Conferências Populares da Glória na capital imperial - preleções públicas nas quais, dentre outros temas, eram vulgarizados assuntos relativos às ciências. Entre 1873, ano de inauguração das conferências, e 1889, quando foram interrompidas, o médico Feliciano Pinheiro de Bittencourt foi o orador que mais vezes se apresentouna tribuna da Glória, como também era conhecido o evento.

Formado em medicina pela Faculdade do Rio de Janeiro, professor do Liceu de Artes e Ofíciqs e, após 1882, do Colégio Pedro II, sendo responsável neste último pela cadeira de história e corografia, Bittencourt abordou temas variados em suas preleções. Medicina, higiene, história, antropologia e evolucionismo foram alguns dos assuntos por ele abordados. Em 1882 publicou um resumo dos assuntos que discorreu na tribuna da Glória na década anterior: 
Apenas vos direi que fiz minha estreia nesta tribuna, tratando do espiritualismo, e do materialismo, mostrando a supremacia do primeiro sobre o segundo deplorável sistema, verdadeira aberração da inteligência humana. Depois ocupei-me com o positivismo, ou materialismo disfarçado, combatendo-o com todas as forças, e mostrando que o erro principal dos adeptos dessa doutrina consiste em quererem fazer de um simples método um sistema completo. [...] Em seguida tratei do darwinismo ou doutrina evolutiva, procurando mostrar que, no estado atual da ciência, é ainda coisa irrisória afirmar-se que o homem descende do macaco aperfeiçoado. ${ }^{2}$

Contrário ao materialismo, Bittencourt muitas vezes criticou esse modo deinterpretação. Para ele, a natureza tinha deser estudada considerando o papel fundamental de Deus. Considerava o método experimental importante, porém acreditava que não deveria ser estendido a tudo. ${ }^{3}$ Desta maneira, alguns fenômenos teriam explicações metafísicas, entretanto, nem por isso deixariam de estar inseridos no campo da ciência.

Com relação ao darwinismo, Bittencourt se referiu a ele como sendo a mesma coisa que "doutrina evolutiva", ou seja, de maneira generalizadora reportou-se à teoria de Darwin como apenas evolucionista. Após a publicação de A origem das espécies tornou-se relativamente comum mencionar o darwinismo, de modo mais amplo, como sinônimo de evolucionismo, mesmo quando não eram expostas proposições vinculadas às ideias do naturalista inglês.

A observação de Bittencourt sobre o homem descender de um "macaco aperfeiçoado" provavelmente estava relacionada com as preleções proferidas pelo médico Augusto Cezar de Miranda Azevedo, em 1875, também no espaço das Conferências Populares da Glória. Em uma de suas apresentações, este orador afirmou que preferia descender de "um macaco aperfeiçoado antes do que de um Adão degenerado!...". ${ }^{4}$ As preleçõesde Azevedo sobre 0 tema tiveram grande repercussão na imprensa, tal frase, por exemplo, provocou grande indignação do jornal católico 0 Apostolo, seguida de polêmica. ${ }^{5}$ Para Bittencourt, que defendia uma interpretação mais teológica da natureza, a afirmação deve ter gerado profunda revolta.

Transcorrido pouco mais de um ano das conferências de Miranda Azevedo, Bittencourt apresentou e analisou, pela primeira vez, a temática do darwinismo na tribuna da Glória.

Discutiu de preferência dois pontos: a embriologia, e a questão importante dos fósseis humanos.

Não aceitou a unidade das diversas espécies animais, nem quanto aos seus caracteres físicos, e muito menos sob o ponto de vista moral.

Disse que os sectários das doutrinas de Carlos Darwin pretendem suscitar essa unidade, apelando para o embrião, para o óvulo, gérmen, ou princípio dos seres, mas que isso não se pode admitir, sendo que não há uma paridade absoluta, ou perfeita semelhança entre os óvulos dessas espécies animais.

Existe apenas para tal ou qual paridade, uns longes de semelhança, que de algum modo podem autorizar a afirmação dos adeptos da escola transformista. ${ }^{6}$

Na perspectiva de Bittencourt, os estudos embriológicos não comprovavam as assertivas de Darwin, porque não existiriam semelhanças significativas entre os embriões humanos e os de outras espécies animais. De acordo com Regina Cândida Ellero Gualtieri, o passado evolutivo de um determinado grupo animal poderia ser conhecido pela análise embriológica de um representante atual, identificando-se características morfológicas dos tipos anteriores presentes no embrião.?

Dentre os darwinistas que defendiam o emprego da embriologia encontrava-se Haeckel, o qual sustentava 0 recapitulacionismo. Para o evolucionista alemão, "o desenvolvimento embriológico das formas superiores poderia servir de guia para se deduzir de forma indireta a evolução da árvore da vida". Desse modo, estabeleceu que a ontogenia recapitulava a filogenia, ou seja, todos os seres passariam por etapas sequenciais as quais equivaleriam às "formas adultas de seus antepassados". 8 
Stephen Jay Gould afirma que a recapitulação foi uma das ideias científicas mais influentes do final do Oitocentos. Estudos de diversas áreas, como a embriologia, a morfologia comparada e a paleontologia, consideravam o conceito de recapitulação como importante chave interpretativa e, com isso, centravam suas pesquisas no intuito de "reconstruir linhagens evolutivas". A recapitulação forneceu preciosos argumentos que pretendiam hierarquizar a humanidade, "os adultos dos grupos inferiores devem ser como as crianças dos grupos superiores, pois a criança representa um ancestral do adulto primitivo". ${ }^{9}$ Os grupos considerados inferiores, por exemplo, eram comparados a crianças brancas do sexo masculino.

Pode ser que Bittencourt tenha lido Haeckel, ou apenas estivesse, mais uma vez, dialogando com Miranda Azevedo. Este, em uma conferência na Glória, apresentou ilustrações de embriões humanos e de cachorros, a fim de mostrar a similitude entre ambos e, com isso, expor provas empíricas da teoria darwinista. As ilustrações expostas haviam sido extraídas da obra de Haeckel. É possível que a imagem abaixo, presente na obra The historyofcreation do evolucionista alemão, tenha sido a apresentada por Miranda Azevedo:

Bittencourt também destacou seu posicionamento contrário à paridade das espécies. Adepto do poligenismo, na sua concepção, as espécies eram diferentes porque haviam sido criadas separadamente. No caso do homem, por
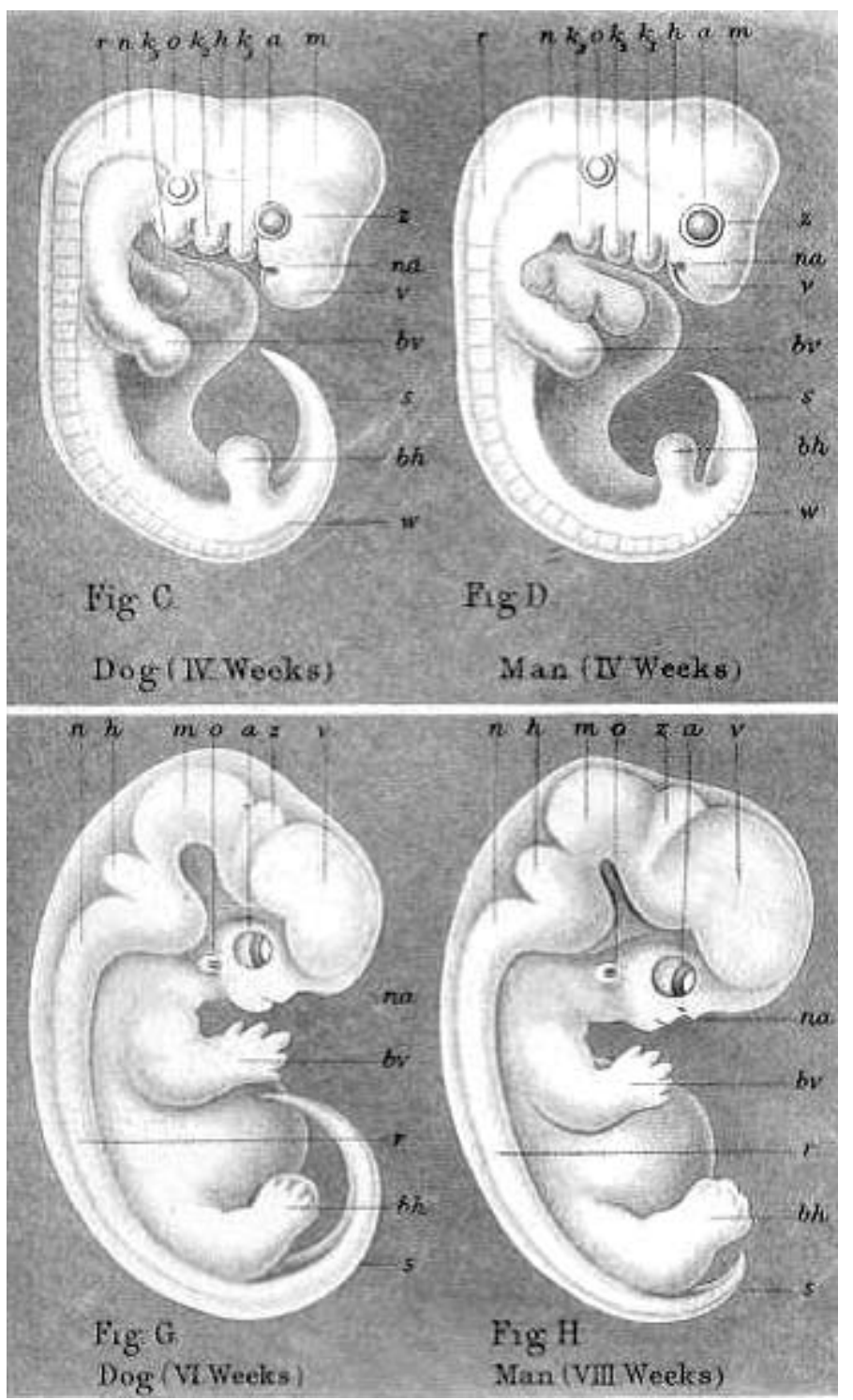

llustração de fetos presentes na obra The history of creation de Haeckel ${ }^{10}$ exemplo, este teria aparecido em diversos pontos da Terra e, por isso, os grupos variados tinham características físicas e morais diferentes.

No que se refere aos fósseis humanos, outro ponto desenvolvido na conferência, Bittencourt afirmou que:

Falando dessas grandes escavações feitas em camadas terrestres pertencentes aos períodos terciário e quaternário, e em épocas e países diferentes, disse que nelas só tem sempre achado camadas de animais antediluvianos, em maior ou menor quantidade, mas que nunca se encontrou até hoje um só esqueleto humano perfeitamente reconhecido por seus caracteres próprios.

Há quem queira sustentar isso, mas sem o menor critério ou fundamento sólido.

Assim se por um lado não se pode negar que a existência dos animais fósseis antediluvianos é uma verdade científica, por outro lado não é muito menos verdade que o homem fóssil parece ser apenas uma engenhosa criação decertos naturalistas, que só quiseram por este meio celebrizar. ${ }^{11}$

Encontrar um fóssil humano poderia representar a comprovação da evolução do homem. Entretanto, a prova não existia, fato que mereceu críticas do conferencista. Para ele, os naturalistas que asseveravam ter descoberto esses fósseis estariam mentindo, teriam inventado tal falácia com o objetivo de se notabilizar perante o meio científico. 
Onze anos após essa preleção, Bittencourt retomou a questão dos fósseis humanos na conferência "Origem das raças: o homem pré-histórico", também realizada na tribuna da Glória. No entanto, apresentou um posicionamento diferente:

A descoberta de fósseis humanos, feita pela primeira vez em 1823 por Amy Roué; os estudos de Boucher, de Perthes, em 1847; de Eduardo Lartet, em 1861, na gruta d'Aurignac; dos Drs. Blake e Wilson, na América do Norte; a descoberta de Lund, nas cavernas da Lagoa Santa, no Brasil, em 1844, e muitas outras, estabeleceram em base sólida a Paleontologia, que veio demonstrar que o homem viveu em meio da fauna quaternária, isto é, no período glacial ou mioceno; que foi contemporâneo do mamute, do mastodonte, do urso das cavernas, etc. E, acrescentou o orador, os sábios hoje vão já mais longe, recuando a existência do homem até o período terciário ou plioceno, firmando-se em dados positivos.

Quanto à data do aparecimento do homem sobre a terra, nada se pode dizer de positivo, uma vez que é impossivel a existência de qualquer documento que nos possa orientar.

Referiu-se o orador aos trabalhos do nosso ilustre compatriota Dr. Lacerda, citados com justo louvor no livro do Sr. Quatrefages - intitulado: A espécie humana.

O Sr. Dr. Lacerda estudou perfeitamente os crânios da Lagoa Santa, bem como outros encontrados no Ceará, publicando a respeito importantes monografias, que muito honram a ciência brasileira perante o mundo civilizado. ${ }^{12}$

Nesta apresentação, Bittencourt passou a admitir a existência de fósseis humanos, porém apenas datados os do período quaternário. 0 orador assegurou que os primeiros fósseis haviam sidos descobertos na década de 1820, citando em seguida outros que foram encontrados nos dois decênios seguintes. 0 que teria feito Bittencourt mudar de opinião da sua conferência de 1876 para esta de 1887, uma vez que todos os exemplos por ele citados já existiam quando de sua preleção anterior? Talvez ele não conhecesse esses trabalhos anteriormente. Contudo, o mais provável é que neste entremeio, além de ter tido contato com outros estudos, ele tenha assistido aos cursos públicos de antropologia do Museu Nacional, ministrado por João Baptista de Lacerda, acompanhado os artigos da revista Archivos do Museu, ido à Exposição Antropológica Brasileira (1882), lido a revista decorrente da exposição e, com isso, tenha alterado a sua maneira de pensar.

0 ponto fulcral estava em qual período geológico teriam vividos os primeiros representantes da espécie humana. Apesar de ressaltar que era difícil estabelecer a data correta do aparecimento do homem na Terra, Bittencourt assegurava que ele não existia até o período terciário, portanto, a sua presença seria mais recente, no quaternário.

A existência de um homem terciário, como precursor do humano, foi polêmica no correr do século XIX. De acordo com Francisco Pelayo-López, o prestígio do paleontólogo francês George Curvier (1769-1832), o qualnegou a existência de fósseis humanos, serviu de obstáculo para a aceitação de trabalhos sobre o homem antediluviano. Entretanto, a partir das décadas de 1830 e 1840, a possibilidade da existência do homem terciário tornou-se foco de análises diversas. Neste período, Jacques Boucher de Perthes (1788-1868) coletou material utilizado na publicação de sua obra Antiquités celtiques elantédiluviennes, 1847-1864, na qual defendeu a existência do homem terciário. Todavia, esta não foi bem recebida entre os pares. ${ }^{13}$

Segundo Pelayo-López, foi na Academia Real de Ciências de Paris que se apresentaram os primeiros trabalhos sobre a presença humana na era terciária. Dentre os quais, o estudo de Louis-Alexis Bourgeois (1819-1878), datado de 1863 e influenciado pelas proposições de Boucher de Perthes, obteve grande repercussão na comunidade científica, seguido de polêmica se estendeu até o início do século XX. A existência de sílex talhado do período terciário seria a prova de que o homem havia vivido neste período e feito tal artefato. A controvérsia, sobre o sílex ser ou não uma evidência, foi complexa, envolvendo tanto criacionistas quanto transformistas. ${ }^{14}$

Se não acompanhou a celeuma diretamente na fonte, certamente Bittencourt teve contato com o debate que se travava e, com isso, passou a admitir a existência dos homens terciários e quaternários. A aceitação da existência desses fósseis como indícios de que o ser humano havia vivido naquele período, todavia, não significava que a partir de então Bittencourt tornara-se adepto do evolucionismo, continuava sendo poligenista. 
Nessa mesma preleção, Feliciano de Bittencourt retomou a questão da existência de um ou mais centros de criação:

O orador desenvolveu estes pontos: descende o homem de um tronco primitivo único, ou de diferentes troncos? Devemos admitir a monogenia ou a poligenia? A unidade ou a pluralidade das espécies?

Qual a data do aparecimento do homem sobre a terra? qual a origem geográfica da espécie humana?

Quanto à primeira questão declarou-se o orador poligenista, isto é, pela pluralidade das espécies, apoiandose sobretudo na teoria de Agassiz sobre os centros múltiplos de produção. Combateu a monogenia, apreciando as ideias de Quatrefages, principal sustentáculo dessa teoria, que hoje tende a ser abandonada..$^{15}$

Partidário do poligenismo, Bittencourt apoiava-se nas proposições de Agassiz ao desenvolver suas ideias. Fora por influência de Samuel George Morton (1799-1851) que o naturalista suíço havia aderido ao poligenismo, na década de 1840. ${ }^{16}$ Nas palavras do orador, o monogenismo era uma teoria que seria abandonada em breve, indicando que já estaria ultrapassada. Para apontar os problemas dessa concepção analítica, fundamentou-se nas proposições de Quatrefages, renomado defensor da abordagem.

De acordo com Jon Roberts, na interpretação de Agassiz, os registros fósseis também serviam para sustentar a proposta de um plano divino de criação. Essas evidências confirmavam as várias criações sucessivas da teoria do catastrofismo, na qual a Terra teria passado por várias catástrofes e, após cada uma delas, as espécies haviam sido recriadas pelas mãos de Deus. Agassiz afirmava não haver provas de que uma espécie descenderia de outra, dado que não existiam fósseis de tipos intermediários, os quais apoiariam empiricamente as propostas evolucionistas. A propósito disso, ele já havia se manifestado contrário à hipótese da transmutação dois anos antes da publicação da obra de Darwin. ${ }^{17}$

Não se pode afirmar que Bittencourt foi partidário do catastrofismo, mas supostamente o conhecia, haja vista que dizia se fundamentar em Agassiz, prestigiado defensor dessa teoria. Porém, assim como o naturalista suíço, o conferencista brasileiro advogava em prol do essencial papel de Deus na criação. Na visão de Agassiz, haveria um plano divino ao distribuir os organismos geograficamente por todo o planeta, colidindo de frente com as teorias que faziam uma interpretação materialista dos fenômenos naturais. Como Deus planejara todas as catástrofes, para Agassiz, cabia ao cientista "desvendar o plano divino por meio da observação científica da natureza. Destinado a esclarecer os desígnios divinos, o cientista deveria ler na 'bíblia da natureza' os caminhos traçados pela onisciência divina". ${ }^{16}$ Assim, "Agassiz não assume que a palavra de Deus estava fora de lugar no discurso científico", ${ }^{19} \mathrm{e}$ da mesma maneira o fazia Bittencourt.

Na conferência seguinte, Feliciano Bittencourt deu continuidade ao tema, a preleção intitulava-se: "Origem das raças; 0 darwinismo; a América pré-histórica". Nessa, o orador apresentou, de modo mais detalhado, seu posicionamento acerca da teoria de Darwin e como a compreendia.

Em seguida ocupou-se com o sistema darwinista ou transformismo, escola que reconhece como chefe o eminente sábio inglês Ch. Darwin, que escreveu uma obra monumental sobre a Origem das Espécies, pretendendo haver descoberto o segredo da gênese dos seres animais e vegetais.

Fez ver que esse sistema procura explicar a origem das espécies superiores por meio de transformações dos seres inferiores. É ininterrupta a cadeia dos seres animais e vegetais, havendo entre as espécies extremas muitos tipos intermediários.

Emitindo a sua opinião disse o orador que o sistema de Darwin se baseia em algumas leis e princípios incontestáveis, mas que não é possível, sem sofismo, chegar-se às conclusões a que chegou o sábio inglês. ${ }^{20}$

Mais uma vezaparece a associação, como conceitos sinônimos, entre darwinismo e evolucionismo de modo mais genérico, este referido como transformismo, indicando que qualquer outra corrente evolucionista era identificada como sendo darwinista, independente das diferenças interpretativas existentes. 
Bittencourt apresentou a teoria de Darwin ligada à ideia de progresso, pois ela explicaria como as espécies inferiores haviam se transformado em superiores. Advertiu, também, que, nessa abordagem, entre esses dois extremos teriam existido tipos intermediários. A associação entre darwinismo e progresso foi recorrente. As mudanças ocorridas durante o processo evolutivo eram compreendidas como alterações de um sistema mais simples a um mais complexo, um movimento de avanço, de progresso. ${ }^{21}$ Entretanto, na ótica Darwin, as modificações não produziam, necessariamente, formações mais elaboradas. ${ }^{22}$ Conforme o naturalista inglês desenvolveu no quarto capítulo de $A$ origem das espécies, dedicado à seleção natural, as transformações ocorriam no sentido de uma melhor adaptação das espécies às condições em que viviam em um determinado período, tal adequação poderia, inclusive, ocorrer no sentido de formar um sistema mais simples. ${ }^{23}$

0 conferencista classificou o sistema do naturalista inglês como sofismático, já que ele estruturava sua abordagem dentro do protocolo da ciência, utilizando alguns princípios "incontestáveis"; entretanto, para chegar as às suas conclusões baseava-se em hipóteses não fundamentadas. Bittencourt falava sobre a inexistência de evidências que provassem as assertivas de Darwin, tais como, exemplares das espécies intermediárias.

Ao dar continuidade à explanação, Bittencourt enunciou:

Certamente são fatos inconcussos a luta pela existência, a seleção natural, a herança ou atavismo, a influência do meio etc. Mas tudo isso não nos pode explicar de modo claro e positivo o como das transformações específicas. Muitos dos supostos tipos intermediários não são conhecidos, logo não se pode afirmar, como o fazem darwinistas, que é ininterrupta a cadeia dos seres vivos.

Declarou positivamente que não se deve aceitar, por indemonstrada, a hipótese de Darwin, quando pretende que o homem não é mais do que um macaco aperfeiçoado!...

Para sustentar semelhante proposição Darwin argumentou com a morfologia dos seres, esquecendo as suas fundamentais diferenças anatômicas e fisiológicas. Este é o vício principal da sua doutrina, aliás muito sedutora. ${ }^{24}$

Bittencourt apresentou como evidências incontestáveis os seguintes pontos da teoria de Darwin: "luta pela existência, a seleção natural, a herança ou atavismo, a influência do meio". Embora não tenha entrado em detalhes como compreendia cada um desses pontos, é possível fazer algumas inferências. Herança e atavismo, por exemplo, foram expostos como sinônimos, desconsiderando assim o fato de 0 atavismo estar relacionado à herança de características de ascendentes longínquos. Por meio da análise dessa preleção, seria possível supor que Bittencourt estivesse de acordo com essas proposições do sistema de Darwin. Contudo, pela leitura do resumo da reunião seguinte, ficou constatado que ele continuava a não concordar com a influência do meio. Ou talvez, e mais provável, ele apenas levantasse como fatos observáveis a existência desses pontos, mas não os considerava como agentes causadores, ou com força suficiente para provocarem transformações evolutivas.

A despeito de reconhecer esses princípios como verdadeiros, Bittencourt, novamente, sublinhou que o grande problema estava em torno da não existência de intermediários entre as espécies atuais e as passadas. Como o médico conferencista acreditava que a criação da Terra e do homem teriam sido trabalhos de Deus, que realizara tal feito com tamanha perfeição, era difícil conceber a ideia de que o produto dessa obra tivesse deser alterado. E o pior, que nos primórdios o homem pudesse ter descendido de um macaco. Afinal, Deus não teria criado o homem a sua imagem $\mathrm{e}$ semelhança, como pregavam as escrituras sagradas? Mais uma vez, retoma-se aqui um ponto que esteve presente na polêmica provocada pelos discursosde Miranda Azevedo, em 1875, quando o jornal católico 0 Apostolo questionou o parentesco humano com o macaco e a origem não divina da Terra e de seus habitantes. ${ }^{25}$

Na terceira conferência consecutiva sobre o mesmo tema, proferida perante numeroso auditório, Feliciano de Bittencourt

Discorreu largamente sobre as leis fundamentais do transformismo, explicando o alcance da luta pela existência, da seleção natural, e da lei da variedade das espécies. 
Disse que as espécies transformam-se, variam quanto aos seus caracteres exteriores, mas que são sempre as mesmas quanto à estrutura íntima, quanto à essência. As condições múltiplas do meio não tem a força de mudarem completamente uma espécie animal ou vegetal, produzindo uma outra nova, diversa inteiramente da primeira.

Fez ver que se quisermos ser lógicos, tirando do darwinismo suas últimas e naturais conclusões, chegaremos ao materialismo absurdo, à negação da existência de Deus. ${ }^{26}$

Nessa preleção, Bittencourt retomou algumas questões sobre o darwinismo discutidas na apresentação anterior. Na sua interpretação, as transformações sofridas pelas espécies seriam apenas superficiais, porque na "essência" continuavam as mesmas, ou seja, não ocorriam modificações. Desta maneira, o médico conferencista reafirmou seu posicionamento contrário ao evolucionismo, sendo ele adepto do poligenismo, não concebia a possibilidade de alterações no correr do tempo, uma vez que os seres teriam sido criados conforme um plano já preestabelecido pelo Criador. Nesse sentido, ele próprio enfatizou que a negação de Deus era um corolário da teoria de Darwin.

Na análise do darwinismo feita por Bittencourt, as mudanças evolutivas ocorridas seriam fruto da ação do meio. Contudo, na visão do orador, o ambiente não teria força para efetuar tais alterações. Dessa forma, ele foi tratado como uma força atuante na abordagem evolucionista de Darwin, que "sempre deixou um espaço para efeitos de uso e desuso e para uma influência direta ou ocasional do ambiente".27

As reflexões de Bittencourt, acerca da teoria darwinista, estavam fundamentadas nas assertivas do médico alemão e grande defensor do materialismo Ludwig Büchner ${ }^{28}$ (1824-1899), referenciado na fonte como Luiz Buchner. Büchner realizou seis conferências nas cidades de Frankfurt, Darmstadt e Worms, entre 1866 e 1868, publicando-as neste ano, sendo que no seguinte a obra seria traduzida para o francês. ${ }^{29}$ É possível que Bittencourt tenha tido contato com as ideias do autor alemão por meio da tradução francesa, haja vista a grande circulação de edições francesas no Brasil. ${ }^{30}$ Isso indica que, provavelmente, o preletor brasileiro não fizera uma leitura direta da obra do naturalista inglês:

Apoiou esta sua opinião nas conferências de Luiz Buchner sobre o darwinismo; ele diz que Charles Darwin não quis, ou não teve coragem de chegar às verdadeiras conclusões de sua doutrina, que são evidentemente materialistas.

Darwin admite quatro ou cinco tipos primitivos animais e vegetais, criados por Deus e de onde se originaram todos os seres orgânicos, que hoje povoam a superfície da terra.

Buchner diz que isto é absurdo, que tudo provém da matéria, pela ação única das forças físicas; para o sábio alemão a matéria é uma só, e não orgânica e inorgânica. Desta é que provém aquela pelo concurso das forças naturais.

O orador demonstrou com muitos argumentos que o materialismo de Buchner é grosseiro e inaceitável, pois pretende justificar o impossível, isto é, a ideia de que a matéria organizada provém da inorgânica; é uma deplorável confusão, que nada adianta, nada resolve. ${ }^{31}$

Defensor de uma visão de mundo teológica, Bittencourt não se furtou de mais uma vez acusar o naturalista inglês de materialista. ${ }^{32}$ Ao dizer que Darwin não teve coragem de se apresentar como materialista, 0 orador evidenciou que esse tipo de posicionamento poderia gerar críticas por levar à negação do papel criador de Deus. Entretanto, Bittencourt afirmou que consoante Darwin alguns seres primitivos haviam sido criados por Deus, indicando que na sua leitura 0 autor de $A$ origem das espécies não chegava a rejeitar plenamente o Criador. Esses seres, por sua vez, teriam originado todos os outros.

Bittencourt contrapôs Darwin e Büchner, e, no seu julgamento, a abordagem deste último era mais reprovável que a do naturalista inglês. Isso porque o cientista alemão defendia calorosamente o materialismo, enquanto Darwin ainda acreditava na existência de seres criados por Deus. Assim, o ponto fulcral para ele era a negação da atuação divina, o que o tocava profundamente enquanto criacionista que era. 
Haeckel também foi alvo das críticas de Bittencourt, ao asseverar que "as opiniões desse ilustre discípulo de Darwin são também demasiadamente ousadas e mistificáveis no terreno da experiência e da observação." ${ }^{33}$ Se referiu às proposições do evolucionista alemão como infundadas, na medida em que não poderiam ser comprovadas empiricamente. Dessa maneira, para desqualificar o evolucionismo, o médico preletor fazia uso do discurso científico, no qual as teorias deveriam estar baseadas em observações e na experiência. As "ousadas e mistificáveis" afirmações de Haeckel poderiam ser as referentes à embriologia adotada pelo cientista, abordagem analítica já depreciada em conferências anteriores.

Ao dar continuidade à preleção, Bittencourt tratou da geração espontânea, afirmando que era "anticientífica, e nem merece as honras da discussão; e corroborou a sua asserção lendo trechos do livro moderno de Mathias Duval sobre 0 darwinismo" ${ }^{34}$ A hipótese da geração espontânea era, para Bittencourt, um absurdo não em função das recentes pesquisas desenvolvidas por Louis Pasteur (1822-1895), mas porque ele era um criacionista e não concebia outra forma de criação que não a divina. 0 médico conferencista tinha conhecimento dos trabalhos de Pasteur, pois em 1885 proferiu uma conferência - "Doutrina microbiana em geral" - na qual discorreu, dentre outros, sobre os trabalhos de Domingos José Freire, acerca da febre amarela, e o de João Baptista de Lacerda, com relação ao beribéri. ${ }^{35}$

0 orador estabeleceu uma relação entre a teoria da geração espontânea e o darwinismo, como se para Darwin a explicação da origem dos seres acontecesse dessa forma. Esta conexão se apresentou de maneira contraditória à afirmativa anterior de Bittencourt, quando confirmou que para Darwin as espécies primitivas haviam sido criadas por Deus. Para tal, apoiou sua análise na interpretação do médico francês Mathias Duval (1844-1907), provavelmente a obra lida foi Le darwinisme, publicada em 1886, um ano antes da realização desta preleção e, por isso mesmo, tendo merecido o destaque de ser um "livro moderno". Isso mostra que Bittencourt estava a par do que era produzido de novo neste campo de investigação. Na extensa publicação, composta por 27 aulas ministradas na Escola de Antropologia entre 1883 e 1884, antes de tratar do darwinismo, Duval abordou a concepção de raça e espécie, o tratamento teórico de Agassiz, Cuvier, Lamarck, Geoffroy Saint-Hilaire, dentre outros. ${ }^{36}$

Com relação à geração espontânea, outros oradores abordaram 0 assunto. Em 1875, também nas Conferências Populares da Glória, o médico Galdino Emiliano das Neves enfocou especificamente o tema. Negou a hipótese da geração espontânea, considerada "improcedente por admitir efeitos sem causa, seres viventes criando-se a si mesmos, esquecendo-se que a matéria é inerte, e como tal incapaz de criar forças e muito menos de organizar-se". Com o propósito de refutá-la, deteve-se nas experiências de Pasteur, conceituado "chefe da cruzada contra a geração espontânea". ${ }^{37}$

Assim como Neves, no ano de 1876, o quartanista de medicina Antonio Cerqueira Lima, em uma preleção proferida no Ateneu Acadêmico, desenvolveu uma análise sobre a geração espontânea. Rejeitou tal hipótese, apresentando dados de outros cientistas a fim de mostrar a inexistência dessa possibilidade. ${ }^{38}$

De volta à preleção de Bittencourt, a fim de finalizá-la ele "tratou das opiniões do ilustre sábio Agassiz, exaradas em seu trabalho sobre as classificações, com as quais em parte concordou, como mais consentâneas com o seu modo de pensar sobre a questão da gênese primitiva do mundo orgânico" ${ }^{39} 0$ orador, apesar de não concordar com todo o sistema de classificação de Agassiz, compartilhava com ele tanto o poligenismo como o criacionismo ${ }^{40} \mathrm{E}$, por isso, era extremamente difícil para o médico brasileiro considerar o darwinismo como uma plausível chave explicativa da natureza.

Após dialogar de maneira mais explícita com a teoria de Darwin, Feliciano Bittencourt expôs uma série de 22 conferências abordando como temática principal a origem do homem no continente americano, referenciadas como sendo um estudo da "América pré-histórica". Sobre os primeiros habitantes que povoaram esta região geográfica, ele concluiu que datavam do período quaternário. ${ }^{41} 0$ objetivo de tais preleções era "demonstrar que é uma única a origem do gentio de toda a América; que a raça é a mesma, dependendo as modalidades das condições de meio e outras", e, por fim, que "0 silvícola americano é autóctone". ${ }^{42}$ Assim, os discursos de Bittencourt visavam comprovar o poligenismo por meio do estudo do caso do homem americano. Partidário da crença na existência de vários centros de criação, 0 
orador pretendia mostrar que um desses foi aqui na América, que, por sua vez, deu origem a todos os habitantes do continente. Centrou boa parte de suas apresentações em questões mais culturais daqueles que povoavam esse espaço antes da chegada do europeu. Sobre os maias, astecas, toltecas e chichimecasenfatizou "sua religião, usos, costumes, agricultura, comércio e indústria". ${ }^{43}$ As exposições foram feitas no intuito de mostrar a semelhança entre os diversos povos, o que atestaria a mesma origem.

Fez ver que todos esses povos, que invadiram a América Central em meados do século XV, pertenciam ao mesmo tronco, à raça Nahualt; sucessivamente uns dominaram os outros chegando a ter os vencedores certo grau de prosperidade e opulência, o que pode verificar pelos monumentos existentes no México, Guatemala, Honduras, Zucatan, e outros lugares, e lendo as narrativas dos conquistadores espanhóis de fins do século $X V^{44}$

Na década de 1880, Bittencourt discursou sobre os indígenas brasileiros sublinhando aspectos variados, como a sua origem e seus hábitos culturais e sociais. Centrou também a atenção nos indígenas da América como um todo, com ênfase nos maias, astecas e incas. 0 resumo de sua primeira preleção sobre o tema, em 1883, foi assim noticiado pelo Jornal do Commercio:

Entrando na matéria da conferência [Feliciano Bittencourt] discutiu a origem primitiva do gentio do Brasil; os cruzamentos que se fizeram com a raça pura; as suas migrações pelo nosso território, mostrando que nada se sabe até hoje de positivo e real a respeito, fundando-se tudo em meras hipóteses, ou probabilidades, que não são de certo a verdade histórica. Dos cruzamentos resultaram as duas famílias de Tupis ou Guaranis, e Tapuias que dominavam o litoral e o interior do país quando os Portugueses chegaram às nossas plagas.

Mostrou detidamente qual a alimentação dos gentios, como a preparavam; quais os seus instrumentos de caça, de pesca, de música, de guerra, etc.; qual o gênero de agricultura a que se entregavam, como se tratavam em suas moléstias, como faziam o enterramento dos mortos, etc.

Falou das tabas ou aldeias, dos casamentos entre os gentios, do [?] dado aos prisioneiros e aos doentes de moléstias crônicas, prendendo sempre por mais de uma hora a atenção do numeroso auditório, que o aplaudiu ao descer da tribuna. ${ }^{45}$

Embora afirmasse que a explicação das origens dos grupos indígenas brasileiros ainda era pautada em hipóteses, segundo Feliciano de Bittencourt, existiu uma raça indígena pura, e dela se originaram as duas grandes famílias existentes: os tupis e os tapuias. ${ }^{46}$ Assim, na abordagem do conferencista, os indígenas existentes desde o período colonial seriam mestiços originários de uma raça pura. Cada agrupamento indígena, este feito em termos linguísticos, era considerado como uma raça específica. Em seguida, se deteve na descrição de alguns aspectos culturais e sociais dos mesmos.

Com relação à origem da tal "raça pura", em uma conferência de 1888, Bittencourt asseverou: "0 fim principal do conferente tem sido demonstrar que é uma única a origem do gentil de toda a América; que a raça é a mesma, dependendo as modalidades das condições de meio e outras. Outrossim, que o silvícola americano é autóctone, isto é, não veio da Ásia, ou de qualquer outro ponto do globo."47

Cinco anos após considerar as teorias sobre a origem dos homens na América como apenas hipotéticas, Bittencourt passou a discutir a questão de maneira mais contundente. Por meio de uma interpretação poligenista, assegurou que todos os indígenas do Novo Mundo eram autóctones e tiveram a mesma origem, "constituindo uma grande raça - a vermelha ou cor de cobre" ${ }^{48} \mathrm{~A}$ cor da pele, dessa maneira, era o parâmetro utilizado pelo médico conferencista para classificar a humanidade; esta também determinaria as características morais do indivíduo.

Como se definia um "sectário confesso"do poligenismo, afirmou que um dos centros de criação fora na América, sustentando que havia acumulado provas diversas para fundamentar as assertivas expostas em suas preleções. ${ }^{49}$ 
Evidências provavelmente coletadas em suas leituras, uma vez que não foi encontrado registro de pesquisas empíricas feitas por Bittencourt. Alguns trabalhos publicados na Revista do Instituto Histórico e Geográfico Brasileiro foram por ele referenciados como excelentes para o estudo acerca da "origem dos selvagens no Brasil". 50

Outra temática sobre a qual Bittencourt versou foi a catequese indígena: "Ocupou-se por último com o importante assunto da catequese e civilização dos índios, mostrando os grandes defeitos do sistema que tem sido empregado até agora, e apontando os meios que supõe mais próprios para colher-se resultado positivo de serviço tão necessário e urgente." ${ }^{\prime 51}$

Consoanteo preletor, catequizar o índio era primordial: a catequese colaboraria para civilizá-lo. Por esse motivo, efetivar tal empreitada era fundamental para o progresso do Brasil. De acordo com Bittencourt, para a boa imagem nacional, o selvagem precisava ser civilizado, o contrário denotaria um país atrasado. Entretanto, esta opinião não era unânime. Existiam aqueles que viam o extermínio indígena como a melhor solução. Na visão de Varnhagen, por exemplo, não havia necessidade de civilizar o índio, porque eles já estavam em um processo de degeneração que levaria à inevitável extinção. Esta posição obteve relativa força nas discussões realizadas no Instituto Histórico e Geográfico Brasileiro, instituição da qual Bittencourt era membro. ${ }^{52}$

Bittencourt ressaltou os problemas na maneira como se dava a catequização, que não tornava frutífera a proposta original: catequizar para civilizar. No que concerne à ausência de eficácia da catequização, Couto de Magalhães, por exemplo, afirmava que era ela que levava à degradação indígena, pois introduzia hábitos degradantes aos povos, preguiça, vícios, embriaguez. ${ }^{53}$ No correr do século XIX, eram comuns as críticas ao modo como era realizado 0 sistema, havia discordância se seriam mais adequados os religiosos brasileiros ou estrangeiros. Optou-se, por fim, pela utilização, na maioria dos aldeamentos, de capuchinos italianos. ${ }^{54}$

Na concepção de Bittencourt, o conhecimento da língua do indígena (nem que fosse por meio de intérpretes) e dos seus "usos e costumes" eram essenciaispara que a catequese se realizasse na prática. Para exemplificar tal necessidade, ele citou os jesuítas que aprenderam o tupi para catequizar os índios do litoral em períodos anteriores. Somente assim seria possível, ao orador, obter "resultados positivos neste importante ramo do serviço público". ${ }^{55}$ Conforme sustenta Kaori Kodama, desde meados do século XIX, a catequização e a civilização dos índios eram consideradas "um ramo do 'serviço público' integrado à pasta ministerial do Império."56

Bittencourt era favorável ao emprego do índio como mão de obra: "Respondeu o orador [Feliciano Bittencourt] às objeções dos que pensam que os índios não servem para o trabalho, lembrando que não há melhores para as indústrias extrativa e pastoril." ${ }^{57}$ Bittencourt sabia que sua afirmação estava na contramão de alguns paradigmas científicos que defendiam a inaptidão dos índios para o trabalho. Todavia ele não estava só. Couto de Magalhães também compactuava com esse posicionamento. A diferença é que Magalhães indicou apenas a pecuária como atividade para o indígena; além desta, Bittencourt assegurava que eles poderiam também dedicar-se às atividades extrativistas. ${ }^{58}$ Assim, para Feliciano Bittencourt era necessário catequizar o índio, a fins de civilizá-lo. Tal programa era uma questão de Estado, pois isso iria colaborar tanto na imagem de um Brasil civilizado, quanto no emprego do indígena como mão de obra.

\section{Considerações finais}

Por meio dessa análise é possível observar que todos os assuntos abordados por Bittencourt foram baseados no poligenismo, do qual era "sectário confesso". ${ }^{99} 0$ orador provavelmente tratou desses mesmos temas em suas aulas de história e corografia que ministrava no Colégio Pedro II. Desta maneira, as Conferências Populares da Glória se tornaram um palanque excelente para que ele pudesse apresentar a um público mais amplo o seu posicionamento acerca da teoria evolucionista de Darwin. Profundo admirador das ideias de Agassiz, assim como este, Bittencourt era 
criacionista e poligenista. E a crença em tais teorias era o que o impedia de aceitar o darwinismo. Neste combate, os pontos principais abordados por Bittencourt foram: a negação do Criador na origem da Terra e dos seus habitantes, e a evolução, pois para ele todos os seres foram planejados divinamente de um modo completo e pronto. Em menor escala, ele também desmereceu as proposições do naturalista inglês no tocante à suposta ancestralidade única entre o homem e o macaco. A questão maior em todas as suas preleções envolvia a luta entre o poligenismo e o monogenismo e entre o criacionismo e o evolucionismo. Cabe marcar, contudo, que todo esse combate ao darwinismo estava dentro da chave interpretativa da ciência, ou seja, em momento algum Bittencourt deixou de explicitar que suas argumentações também eram científicas.

\section{Notas e referências bibliográficas}

Karoline Carula é doutora em História Social pela Universidade de São Paulo. E-mail: karolinecarula@yahoo.com.br.

1 Foi sócio do Instituto Histórico e Geográfico Brasileiro, da Sociedade de Geografia do Rio de Janeiro e era membro da Associação Promotora da Instrução, estas duas últimas instituições fundadas, dentre outros, pelo conselheiro Manoel Francisco Correia, também criador e diretor das Conferências Populares da Glória.

2 BITTENCOURT, Feliciano Pinheiro de. Conferenciasefectuadas na escola da Gloria. Rio de Janeiro: Typographia e Lithographia a vapor, encadernação e Livraria Lombaerts \& C., 1882, p. 6, grifos do autor.

3 Cabe evidenciar que esse tipo de interpretação ocorreu em outros países. Na Bolívia, por exemplo, José de los Santos Taborga, professor de teologia e arcebispo de Sucre, empregou uma análise semelhante à de Bittencourt. Para o boliviano, o positivismo abusava na utilização do método experimental ao tentar aplicá-lo a todas as ciências. Taborga também se posicionou contrário ao materialismo evolucionista de Haeckel e de Spencer. ARGUETA VILLAMAR, Arturo. El darwinismo en Iberoamérica: Bolívia y México. Madrid: Consejo Superior de Invetigaciones Científicas, Cararata, 2009, p. 186-9.

4 AZEVEDO, Augusto Cezar de Miranda.Darwinismo: seu passado, seu presente e seu futuro. Conferencias Populares, Rio de Janeiro: Typ. Imp. e Const. de J. Villeneuve \& C., n. 4, jan. 1876, n. 4, p. 47.

5 CARULA, Karoline. A tribuna da ciência: as Conferências Populares da Glória e as discussões do darwinismo na imprensa carioca (1873-1880). São Paulo: Annablume; Fapesp, 2009.

6 Gazeta de Noticias, 09/11/1876, grifos do autor.

7 GUALTIERI, Regina Cândida Ellero.Evolucionismo no Brasil: ciência e educação nos museus 1870-1915. São Paulo: Editora Livraria da Física, 2008 , p. 25.

8 GOULD, Stephen Jay. A falsa medida do homem. Tradução de Valter Lellis Siqueira. 2.ed. São Paulo: Martins Fontes, 1999, p. 112, grifo do autor.

$9 \quad$ Ibidem, p. 112-3, grifos do autor.

10 HAECKEL, Ernst. The history of creation: or the development of the earth and its inhabitants by the action of natural causes. A popular exposition of the doctrine of evolution in general, and of that of Darwin, Goethe, and Lamarck in particular.V. I. London: Henry S. King \&Co., 1876.Imagem entre as páginas 306 e 307.

11 Gazeta de Noticias, 09/11/1876, grifos do autor.

12 Jornal do Commercio, 11/10/1887, grifos do autor.

13 PELAYO-LÓPEZ, Francisco. ¿“Hombre terciario” o precursor humano?: Sílex, transformismo y los orígenes de la humanidad. In: DOMINGUES, Heloisa Maria Bertol; SÁ, Magali Romero; PUIG-SAMPER, Miguel Ángel; RUIZ GUTIÉRREZ, Rosaura. (Orgs.). Darwinismo, meio ambiente e sociedade. São Paulo: Via Lettera, 2009, p. 161-76.

14 PELAYO-LÓPEZ, op. cit.

15 Jornal do Commercio,11/10/1887, grifos do autor.

16 MACHADO, Maria Helena Pereira Toledo. A ciência norte-americana visita a Amazônia: entre o criacionismo cristão e o poligenismo "degeneracionista". Revista USP, São Paulo, set./nov. 2007, n.75, p. 74.

17 ROBERTS, Jon. Louis Agassiz: poligenismo, transmutação e a metodologia científica. Uma reavaliação. In: DOMINGUES, Heloisa Maria Bertol; SÁ, Magali Romero; PUIG-SAMPER, Miguel Ángel; RUIZ GUTIÉRREZ, Rosaura (Orgs.). Darwinismo, meio ambiente e sociedade. São Paulo: Via Lettera; Rio de Janeiro: MAST, 2009, p. 73-100.

18 MACHADO, op. cit., p. 70.

19 ROBERTS, op. cit., p. 86.

20 Jornal do Commercio, 17/10/1887.

21 ARGUETA VILLAMAR, op. cit. MONTSERRAT, Marcelo. La mentalidad evolucionista en la Argentina: una ideología del progreso. In: GLICK, Thomas F., RUIZ GUTIÉRREZ, Rosaura; PUIG-SAMPER, Miguel Ángel (Ed.). El darwinismo en España y Iberoamérica. México, DF: Universidad Autónoma de México; Madrid: Consejo Superior de Investigaciones Científicas, Ediciones Doce Calles, 1999, p. 16-46. RUSE, Michael. Evolución y progreso: crónica de los conceptos. In: 
WAGENSBERG, Jorge; AGUSTÍ, Jordi (Eds.). El progreso ¿Un concepto acabado o emergente? Traducción de Ambrosio García Leal. Barcelona: Tusquets Editores, 1998, p. 67-106.

22 MAYR, Ernst. Biologia, ciência única: reflexões sobre a autonomia de uma disciplina científica. São Paulo: Companhia das Letras, 2005.GOULD, Stephen Jay. Darwin e os grandes enigmas da vida. Tradução de Maria Elizabeth Martinez. 2.ed. São Paulo: Martins Fontes, 2006. GOULD, Stephen Jay. Lance de dados: a idéia de evolução de Platão a Darwin. Tradução de Sergio Moraes Rego. Rio de Janeiro: Record, 2001;RUSE, Michael. Evolución y progreso: crónica de los conceptos. In: WAGENSBERG, Jorge; AGUSTÍ, Jordi (Eds.). El progreso iUn concepto acabado o emergente? Traducción de Ambrosio García Leal. Barcelona: TusquetsEditores, 1998, p. 67-106.

23 DARWIN, Charles. On the origin of species by means of natural selection, or the preservation of favoured races in the struggle for life. New York: D. Appleton and Company, 1864.

24 Jornal do Commercio, 17/10/1887, grifos do autor.

25 CARULA, op. cit.

26 Jornal do Commercio,31/10/1887, grifos do autor.

27 MAYR, op. cit., p. 128. Nesta perspectiva, Argueta Villamar afirma que: “No se puede afirmarse que la idea sobre el uso y desuso sea una de las nociones más importantes de la teoría evolucionista darwiniana, pero lo increíble es que se haya popularizado tanto, y sobre todo que en América Latina se haya difundido como uno de los elementos centrales de la teoría darwiniana, cuando es central en la teoría de Lamarck, pero relatico en la de Darwin." ARGUETA VILLAMAR, op. cit., p. 75.

28 Suas principais discussões sobre a filosofia materialista foram publicadas na obra Força e matéria, em 1855.

29 BÜCHNER, Louis. Conférences sur la théoriedarwinienne de la transmutation des espèces et de l'apparition du monde organique. Application de cettethéorie à I'homme. Sesrapportsavecladoctrineduprogrès et aveclaphilosophiematérialistedupassé et du present. Traduit par Auguste Jacquot. Leipzig: Théodore Thomaz, Libraire-Éditeur; Paris: C. Reinwald, Libraire-Éditeur, 1869.

30 FERREIRA, Tania Maria Bessone da Cruz. Palácios de destinos cruzados: bibliotecas, homens e livros no Rio de Janeiro, 1870-1920. Rio de Janeiro: Arquivo Nacional, 1999.

31 Jornal do Commercio, 31/10/1887.

32 De fato, após a publicação de $A$ origem das espécies, Darwin teve que trabalhar com a pecha de ateu. DESMOND, Adrian; MOORE, James. Darwin: a vida de um evolucionista atormentado. 5. ed. Tradução de Cynthia Azevedo. São Paulo: Geração Editorial, 2007.

33 Jornal do Commercio, 31/10/1887.

34 Idem, ibidem.

35 Ibidem, 18/11/1885. Sobre Domingos Freire e sua luta contra febre amarela conferir: BENCHIMOL, Jaime Larry. Dos micróbios aos mosquitos: febre amarela e a revolução pasteuriana no Brasil. Rio de Janeiro: Editora Fiocruz/Editora UFRJ, 1999.

36 DUVAL, Mathias. Le Darwinisme.Leçonsprofesées a l'École d'Anthropologie. Paris: Adrien Delahave et ÉmileLecrosnier, 1886.

37 O Globo, 24/10/1875.

38 Jornal do Commercio, 10/07/1876.

39 Ibidem, 31/10/1887.

40 A respeito do posicionamento poligenista e criacionista de Agassiz conferir: MACHADO, op. cit.

41 Jornal do Commercio, 07/11/1887, grifos do autor.

42 Ibidem, 04/07/1888, grifos do autor.

43 Ibidem, 02/08/1888.

$44 \quad$ Ibidem.

45 Ibidem, 15/05/1883, grifos do autor.

46 Com relação à origem dos grupos indígenas brasileiros, havia também aqueles que defendiam uma ascendência asiática para os mesmos. Tal posicionamento foi acatado, por exemplo, por Gonçalves Dias (1823-1864), paraeste, "os tupis formavam uma raça invasora superior que, vinda do norte, havia conquistado os grupos tapuias de origem mongol e tomado suas mulheres. 0 resultado teria sido a decadência dos tupis mais civilizados, devido à sua integração de uma população mais bárbara e atrasada." Já Francisco Adolfo de Varnhagen (1816-1878) propunha que "os tupis eram um povo invasor, vindo do norte, aparentado originalmente aos egípcios e fenícios". MACHADO, Maria Helena Pereira Toledo. Os tupis e a turânia: hipóteses sobre a origem do homem e da civilização nas Américas na segunda metade do século XIX e primeiras décadas do XX. In:Brasil a vapor: raça, ciência e viagem no século XIX. Tese (Livre-Docência) - Faculdade de Filosofia Letras e Ciências Humanas, Universidade de São Paulo, São Paulo, 2005, p. 174-175.

47 Jornal do Commercio,04/07/1888, grifos do autor.

48 Ibidem, 28/08/1888.

49 Ibidem, 14/08/1889.

50 bidem, 24/09/1889. Feliciano de Bittencourt citou os seguintes autores, que publicaram artigos sobre o tema na revista do Instituto: Varnhagen, Gonçalves Dias, Accioli de Cerqueira e Silva, Candido Mendes, Joaquim Norberto e engenheiro Tocantins.

51 Jornal do Commercio, 12/11/1882, grifos do autor.

52 Varnhagen foi radical, chegando a propor o retorno das bandeiras particulares, com o intuito de capturar indígenas. MONTEIRO, John Manuel. Entre 0 gabinete e o sertão: projetos civilizatórios, inclusão e exclusão dos índios no Brasil Imperial. In: MONTEIRO, John Manuel.Tupis, tapuias e historiadores: estudos de história indígena e do indigenismo. Tese (Livre Docência) - Universidade Estadual de Campinas, Campinas, SP, 2001, p. 147-8.

53 MONTEIRO, op. cit., p. 152-3.

54 KODAMA, Kaori. Os índios no Império do Brasil: a etnografia do IHGB entre as décadas de 1840 e 1860. Rio de Janeiro: Editora Fiocruz; São Paulo: 
Edusp, 2009.

55 Jornal do Commercio, 26/11/1883.

56 KODAMA, op. cit., p. 244.

57 Jornal do Commercio, 26/11/1883.

58 Outro intelectual a defender o emprego da mão de obra indígena foi o Frei Serafim de Gorízia (1829-1918), em seus escritos feitos próximos à abolição, contrariando o que era sustentado por muitas teorias científicas. MONTEIRO, op. cit., p. 162.

Jornal do Commercio, 14/08/1889.

[Recebido em Setembro de 2012. Aprovado para publicação em Outubro de 2012] 